\title{
Two Novel Mutations in the Argininosuccinate Lyase Gene in Iranian Patients and Literature Review
}

\author{
Parastoo Rostami, ${ }^{1,2,3,}$ Johannes Häberle, ${ }^{4}$ Arya Setoudeh, ${ }^{2,3}$ Johannes Zschocke, ${ }^{5}$ and Fatemeh \\ Sayarifard ${ }^{1,2,3}$ \\ ${ }^{1}$ Growth and Development Research Center, Tehran University of Medical Sciences, Tehran, IR Iran \\ ${ }^{2}$ Department of Pediatrics, Tehran University of Medical Sciences, Tehran, IR Iran \\ ${ }^{3}$ Children's Medical Center, Pediatrics Center of Excellence, Tehran, Iran \\ ${ }^{4}$ Devision of Metabolism, University Children's Hospital Zurich and Children's Research Centre, Zurich, Switzerland \\ ${ }^{5}$ Division of Human Genetics, Medical University Innsbruck, Innsbruck, Austria \\ "Corresponding author: Parastoo Rostami, Growth and Development Research Center, Tehran University of Medical Sciences, Tehran, IR Iran. E-mail: drp_rostami@yahoo.com
}

Received 2017 June 25; Revised 2017 February 17; Accepted 2017 April 14.

\begin{abstract}
Introduction: The argininosuccinate lyase (ASL) gene encodes argininosuccinate lyase (ASL), which is one of the six enzymes of the urea cycle that detoxifies blood ammonia. Argininosuccinate lyase deficiency impairs the function of the urea cycle and causes hyperammonemia, neurodevelopmental delay and hepatopathy.

Case Presentation: Here we report two patients with argininosuccinate aciduria. They were treated with peritoneal dialysis and scavenger drugs. Molecular genetic testing showed two novel homozygous mutations, c.146T > G (p.Leu49Arg) in exon 3 and c.1144$1 G>C$ in intron 15 of the ASL gene.

Conclusions: This report intends to underline the importance of pediatricians being aware of the existence of a metabolic disease in any ill neonate. Diagnosis of urea cycle disorders is particularly important because of availability of effective treatment options.
\end{abstract}

Keywords: Hyperammonemia, Argininosuccinate Lyase, Argininosuccinic Aciduria, Urea Cycle

\section{Introduction}

Amino acids are degraded into organic acids and free ammonia which is toxic to the central nervous system. The urea cycle is the metabolic pathway that transforms ammonia to urea which can be excreted via the kidneys from the body. A deficiency of any of the enzymes of the cycle result in urea cycle disorders (UCDs) that cause lifethreatening hyperammonemia. Argininosuccinate lyase (ASL) is one of the six liver enzymes comprising the urea cycle that hereby contributes to removal of waste nitrogen and to generation of arginine (1). The ASL enzyme is a protein of 464 amino acids with a molecular weight of about $52 \mathrm{kD}$ that is encoded by ASL gene. The human ASL gene was cloned in 1986 and is located on chromosome 7q11.21 it is about $35 \mathrm{~kb}$ in length and consists of 17 exons (of which 16 are protein-coding) with the first exon containing most of the $5^{\prime}$-untranslated region (2). Argininosuccinic aciduria (ASA, OMIM \#207900) is a clinically heterogeneous, autosomal recessive disease due to ASL deficiency. It was first reported by Solitare et al in 1969 (3). Two forms of ASA have been described: an early-onset, severe type and a late-onset type (2). In the severe form, signs and symptoms appear already after the first 24 hours after birth with vomiting, poor feeding, lethargy, respiratory distress which may all progress to coma and death if left untreated. The clinical manifestations of the late onset, subacute form consist of hepatomegaly and hepatopathy, bleeding tendency, failure to thrive, intellectual disability, seizures, dry and brittle hair and gallstones $(1,4,5)$. The biochemical diagnosis of ASA is based on the combination of hyperammonemia with high plasma levels of glutamine, alanine, citrulline, and specifically argininosuccinate in urine and/or plasma. Enzyme assays and genetic analyses can be used for confirmation. We therefore report here two novel mutations in the ASL gene that caused the severe form of the disease in our patients.

\section{Case Presentation}

\subsection{Case 1}

A 3-day-old male infant was referred to the emergency ward because of vomiting, poor feeding, lethargy and respiratory distress. He was the second child of a consanguineous marriage, born with a weight of $3500 \mathrm{~g}$, length of $50 \mathrm{~cm}$, and a head circumference of $36 \mathrm{~cm}$. The first child was normal. The patient was found to have hepatomegaly and hypotonia, and was admitted to the neonatal intensive care unit. Laboratory tests showed severe 
hyperammonemia of $240 \mu \mathrm{mol} / \mathrm{L}$ (normal < 65) without metabolic acidosis, and an elevation of aspartate aminotransferase AST (120 IU/l, normal up to 35) and alanine aminotransferase ALT (145 IU/l, normal up to 41). Serum amino acid analysis revealed an elevated level of citrulline (150 $\mu \mathrm{mol} / \mathrm{L}$, normal 8 - 47), glutamine $(1050 \mu \mathrm{mol} / \mathrm{L}$, normal 396 - 746) and alanine ( $1250 \mu \mathrm{mol} / \mathrm{L}$, normal 20 - 600) together with decreased levels of arginine $(25 \mu \mathrm{mol} / \mathrm{L}$, normal 40 -160). Argininosuccinate was markedly elevated in analysis of acylcarnitine to $9.5 \mu \mathrm{mol} / \mathrm{L}$ (normal1-2). The patient was treated with intravenous sodium benzoate (300 $\mathrm{mg} / \mathrm{kg} /$ day), sodium phenylbutyrate (300 $\mathrm{mg} / \mathrm{kg} /$ day) and L-arginine $(700 \mathrm{mg} / \mathrm{kg} / \mathrm{day})$ which failed to reduce ammonia levels or to improve the clinical/neurological situation after 12 hours. Therefore peritoneal dialysis was started and then the level of ammonia reduced significantly after 12 hours. There were several episodes of seizures. Currently, the patient is seven months old; he has developmental delay, axial hypotonia but hypertonia and hyperreflexia in limbs. He has also episodes of generalized seizure despite antiepileptic treatment. Brain magnetic resonance imaging (MRI) at age six months revealed diffuse brain atrophy. In addition he has failure to thrive, anorexia, intermittent vomiting, poor weight gain and hepatopathy. $\mathrm{He}$ is receiving sodium benzoate $(300 \mathrm{mg} / \mathrm{kg} /$ day), phenylbutyrate $(300 \mathrm{mg} / \mathrm{kg} /$ day), IL-arginine $(700 \mathrm{mg} / \mathrm{kg} /$ day) and low protein diet $(2 \mathrm{gr} / \mathrm{kg} / \mathrm{day})$ with a combination of natural protein and essential amino acids. During catabolic states, because of poor response to drugs, peritoneal dialysis is done.

\subsection{Case 2}

A 4-day-old male infant was admitted to hospital because of generalized tonic-clonic seizures. He was the second child of healthy parents who were first cousins. His older brother was normal. He was born full term with a weight of $3100 \mathrm{gr}$, length of $48 \mathrm{~cm}$, and a head circumference of $33 \mathrm{~cm}$. He showed poor feeding, vomiting, lethargy, and drowsiness, starting one day before admission. On examination he had a bulged fontanel, hepatomegaly, hypotonia and was thus admitted to the neonatal intensive care unit. Laboratory tests revealed severe hyperammonemia of $450 \mu \mathrm{mol} / \mathrm{L}($ normal $<65)$ with mild metabolic acidosis ( $\left.\mathrm{pH}=7.25, \mathrm{HCO}_{3} 16 \mathrm{mEq} / \mathrm{L}\right)$, elevated aspartate aminotransferase AST $(220 \mathrm{IU} / \mathrm{L}$, normal $<35)$, alanine aminotransferase ALT $(150 \mathrm{IU} / \mathrm{L}$, normal $<41)$. Serum amino acid analysis showed elevated levels of citrulline $(180 \mu \mathrm{mol} / \mathrm{L}$, normal 8 - 47), glutamine ( $1110 \mu \mathrm{mol} / \mathrm{L}$, normal 396 - 746) and alanine $(1400 \mu \mathrm{mol} / \mathrm{L}$, normal 20 - 600) with a low concentration of arginine $(20 \mu \mathrm{mol} / \mathrm{L}$, normal $40-160)$. Argininosuccinate in plasma was markedly elevated to $20 \mu \mathrm{mol} / \mathrm{L}$ (normal $1-2$ ). As in patient 1 , the patient was initially treated with nitrogen scavenging drugs and L-arginine. Because of poor response to this treatment, peritoneal dialysis was started and the level of blood ammonia decreased within 24 hours. At present, he is fourteen months and hyperammonemia is controlled by sodium benzoate (500 $\mathrm{mg} / \mathrm{kg} /$ day), L-arginine $(700 \mathrm{mg} / \mathrm{kg} /$ day) and low protein diet $(2 \mathrm{gr} / \mathrm{kg} /$ day) with a combination of natural protein and essential amino acids as in patient 1 . At age 14 months, he started rolling and crawling but cannot yet sit. His liver is enlarged and he has failure to thrive, hypotonia and $\mathrm{mi}$ crocephaly.

\subsection{Genetic Studies}

Based on the clinical and metabolic findings, argininosuccinic aciduria (ASA) was suspected in both patients. To confirm the diagnosis, ASL mutation analysis was performed by PCR amplification and Sanger sequencing of all coding exons and adjacent intron sequences of the gene, using standard protocols. In case 1 a novel homozygous variant c.146T > G was identified in exon 3 of the ASL gene. This missense mutation is predicted to cause an amino acid change p.Leu49Arg, which concerns a high conserved amino acid. Different in silico analysis programs (SIFT, GVGD, PolyPhen, Mutation Taster) predict a disease causing effect; it may affect helix formation within the ASL protein. It has not been recorded in the relevant genetic variant or ASL mutation databases. In case 2 a homozygous variant c.1144-1G $>C$ was identified that involves the last nucleotide preceding exon 16 . This splice mutation is predicted to remove the consensus acceptor (3') splice site of intron 15 and to result in aberrant splicing of the pre-mRNA-transcripts of the ASL gene, possibly skipping exon 16. This most likely leads to complete absence of ASL protein function. The variant has not been previously reported as a disease-causing mutation; it has been recorded with an allele frequency of $<1 \times 10^{-5}(1: 118,556)$ in the ExAC Database (single heterozygous control individual from South Asia; http://exac.broadinstitute.org/variant/7$65557543-\mathrm{G}-\mathrm{C})$. In both families, both parents were heterozygous for the respective mutation, confirming obligate parental carrier status and segregation of the mutation.

\section{Discussion}

The presentation of ASA is non-specific which is often misinterpreted as bacterial sepsis or anoxic-ischemic encephalopathy (4). In the absence of treatment, lethargy, seizures, and coma worsen, resulting in death (2). Our patients showed a typical neonatal form of ASA manifesting as vomiting, poor feeding, lethargy and respiratory distress, somnolence and seizures on the third and fourth 
day of life. As a metabolic disease was suspected from the very beginning, the diagnosis of ASA was made very early and treatment was started immediately after first symptoms. To confirm the diagnosis of ASA in the patients, molecular genetic testing of the ASL gene was carried out which revealed the novel missense mutation c.146T $>\mathrm{G}$ (p.Leu49Arg) in exon 3 and the splicing mutation c.1144$1 \mathrm{G}>\mathrm{C}$ in intron 15 , both in a homozygous state. ASA is genetically heterogeneous and identified mutations are frequently novel in the respective family, making a prediction of the functional effects more difficult. Both mutations identified in our patients are suggestive of complete or substantial loss of protein function in line with severe neonatal onset ASA. So far, 143 mutations in ASL gene reported in the literature and the most common mutation were missense/nonsense (the human gene mutation database). Importantly for genetic counselling, knowledge of the mutations will allow prenatal diagnosis in later pregnancies. Correlation between genotype and phenotype is not yet clearly defined $(6,7)$, so it is important to report every mutation and genotype along with the clinical and biochemical phenotype of the patient all around the world.

This report intends to underline the importance of pediatricians being aware of the existence of a metabolic disease in any ill neonate. Diagnosis of urea cycle disorders is particularly important because of availability of effective treatment options. In the case of ASA, and likewise in many other metabolic diseases, molecular genetic testing is necessary to confirm the diagnosis and offers the option of prenatal testing in future pregnancies.

\section{References}

1. Nassogne MC, Heron B, Touati G, Rabier D, Saudubray JM. Urea cycle defects: management and outcome.JInherit Metab Dis. 2005;28(3):407-14. doi: 10.1007/s10545-005-0303-7. [PubMed: 15868473].

2. Trevisson E, Salviati L, Baldoin MC, Toldo I, Casarin A, Sacconi S, et al. Argininosuccinate lyase deficiency: mutational spectrum in Italian patients and identification of a novel ASL pseudogene. Hum Mutat. 2007;28(7):694-702. doi: 10.1002/humu.20498. [PubMed: 17326097].

3. Solitare GB, Shih VE, Nelligan DJ, Dolan TF. Argininosuccinic aciduria: clinical, biochemical, anatomical and neuropathological observations. J Ment Defic Res. 1969;13(3):153-70. [PubMed: 5823673].

4. Mori T, Nagai K, Mori M, Nagao M, Imamura M, Iijima M, et al. Progressive liver fibrosis in late-onset argininosuccinate lyase deficiency. Pediatr Dev Pathol. 2002;5(6):597-601. doi: 10.1007/s10024-002-0109-7. [PubMed: 12370774].

5. Ficicioglu C, Mandell R, Shih VE. Argininosuccinate lyase deficiency: longterm outcome of 13 patients detected by newborn screening. Mol Genet Metab. 2009;98(3):273-7. doi: 10.1016/j.ymgme.2009.06.011. [PubMed: 19635676].

6. Linnebank M, Homberger A, Rapp B, Winter C, Marquardt T, Harms E, et al. Two novel mutations (E86A, R113W) in argininosuccinate lyase deficiency and evidence for highly variable splicing of the human argininosuccinate lyase gene.J Inherit Metab Dis. 2000;23(4):308-12. [PubMed: 10896281].

7. Linnebank M, Tschiedel E, Haberle J, Linnebank A, Willenbring H, Kleijer WJ, et al. Argininosuccinate lyase (ASL) deficiency: mutation analysis in 27 patients and a completed structure of the human ASL gene. Hum Genet. 2002;111(4-5):350-9. doi: 10.1007/s00439-002-0793-4. [PubMed: 12384776]. 